\title{
BMJ open Systematic literature review of templates for reporting prehospital major incident medical management
}

\author{
Sabina Fattah, ${ }^{1,2}$ Marius Rehn, ${ }^{1,3,4}$ Eirik Reierth, ${ }^{5}$ Torben Wisborg ${ }^{2,6}$
}

To cite: Fattah S, Rehn M, Reierth $\mathrm{E}$, et al. Systematic literature review of templates for reporting prehospital major incident medical management. BMJ Open 2013:3:e002658

doi:10.1136/bmjopen-2013002658

- Prepublication history for this paper is available online. To view these files please visit the journal online (http://dx.doi.org/10.1136/ bmjopen-2013-002658).

Received 30 January 2013

Revised 25 June 2013

Accepted 27 June 2013

${ }^{1}$ Department of Research and Development, Norwegian Air Ambulance Foundation, Drøbak, Norway

${ }^{2}$ Anaesthesia and Critical Care Research Group, Faculty of Health Sciences, University of Tromsø, Tromsø, Norway

${ }^{3}$ Network of Medical

Sciences, Field of Prehospital Critical Care, University of Stavanger, Stavanger, Norway

${ }^{4}$ Department of Anaesthesia and Intensive Care, Akershus University Hospital, Lørenskog, Norway

${ }^{5}$ Science and Health Library, University Library of Tromsø University of Tromsø,

Tromsø, Norway

${ }^{6}$ Department of

Anaesthesiology and Intensive Care, Hammerfest Hospital, Finnmark Health Trust, Hammerfest, Norway

Correspondence to

Sabina Fattah;

sabina.fattah@

norskluftambulanse.no

\section{ABSTRACT}

Objective: To identify and describe the content of templates for reporting prehospital major incident medical management

Design: Systematic literature review according to PRISMA guidelines.

Data sources: PubMed/MEDLINE, EMBASE, CINAHL, Scopus and Web of Knowledge. Grey literature was also searched.

Eligibility criteria for selected studies: Templates published after 1 January 1990 and up to 19 March 2012. Non-English language literature, except Scandinavian; literature without an available abstract; and literature reporting only psychological aspects were excluded.

Results: The main database search identified 8497 articles, among which 8389 were excluded based on title and abstract. An additional 96 were excluded based on the full-text. The remaining 12 articles were included in the analysis. A total of 107 articles were identified in the grey literature and excluded. The reference lists for the included articles identified five additional articles. A relevant article published after completing the search was also included. In the 18 articles included in the study, 10 different templates or sets of data are described: 2 methodologies for assessing major incident responses, 3 templates intended for reporting from exercises, 2 guidelines for reporting in medical journals, 2 analyses of previous disasters and 1 Utstein-style template.

Conclusions: More than one template exists for generating reports. The limitations of the existing templates involve internal and external validity, and none of them have been tested for feasibility in real-life incidents.

Trial registration: The review is registered in PROSPERO (registration number: CRD42012002051).

\section{INTRODUCTION}

Major incidents, such as natural disasters, accidents and terrorist attacks, affect millions of lives each year. In 2011, natural disasters alone killed more than 30000 people and injured 244 million people worldwide. The 332 natural disasters in 2011 caused the

\section{ARTICLE SUMMARY}

Article focus

- Identify templates that enable systematic and uniform reporting of prehospital major incident medical management.

- Appraise the data fields in the included templates regarding internal and external validity.

Key messages

- Templates for reporting major incident medical management exist in different formats, but none have been tested for feasibility.

- A template for generating reports from the prehospital phase with clearly defined data variables enabling comparative analysis is needed.

Strengths and limitations of the study

- A systematic review following the preferred reporting items for systematic reviews and meta-analyses guidelines.

- The protocol was published and deviations from protocol are revealed in the study report.

- Only English and Scandinavian language literature was included.

highest economic damage ever recorded; Asia was the continent most often hit, followed by the Americas, Africa, Europe and Oceania. This regional distribution of disaster resembles the profile observed from 2001 to 2010. Over the last decade, China, the USA, the Philippines, India and Indonesia were the five countries most frequently hit by natural disasters. ${ }^{1}$

Although disaster medicine can be traced back to the Middle Ages, it has become a distinct scientific discipline in only the last 60 years. $^{2}$ An evolving trend in disaster medicine calls for improved reporting of major incidents in order to increase the level of science within this field. ${ }^{3-8}$ Previous expert group processes defined uniform data sets for reporting in both emergency medicine in general $^{9} 10$ and in disaster medicine specifically. ${ }^{11}{ }^{12}$ These templates were designated as Utstein-style templates after the Norwegian 
monastery where they were developed. Qualitative research methods have also been used to identify areas within prehospital critical care and major incident management that require further research. ${ }^{13}{ }^{14} \mathrm{~A}$ recent review identified data from mass gatherings as nonuniform and called for consistent data to enable future research. ${ }^{15}$ The importance of evaluating disaster exercises using predefined, high-quality data has also been discussed as a potential for improving disaster health management ${ }^{16}$ and for comparing outcomes from different exercises. ${ }^{17}$ The analysis of standardised data from previous incidents can allow decision-makers to make well-informed decisions. ${ }^{18}$

This systematic review was designed to identify and describe the content of templates for reporting prehospital major incident medical management. The questions being asked in this systematic review were: which data are reported in the existing templates (data extraction), and are the templates internally and externally valid with regard to the methodology with which they were developed and the data they are reporting (quality appraisal)? The need for a template for uniform reporting was assessed based on the findings. To the best of our knowledge, no similar studies have been performed or registered in the Cochrane or Prospero databases.

\section{METHODS}

\section{Search strategy}

A systematic literature search was performed to identify templates published after 1 January 1990 and up to 19 March 2012. ${ }^{19}$ The controlled vocabulary of Medical Subject Headings (MeSH) from PubMed, including subheadings, publication types and supplementary concepts, was used. The search was performed between 24 February 2012 and 19 March 2012. A systematic search of the grey literature was performed 25-29 June 2012.

In the main database search, three sets of entry terms were applied and combined (figure 1). The first set of entry terms describes major incidents. The second set of entry terms describes templates. In addition to the MeSH terms in the first two sets, a third set of entry terms with free search phrases was included. For the grey literature search, only two sets of entry terms were combined. $^{19}$

Inclusion criteria

- Templates reporting prehospital major incident medical management.

- Templates published after 1 January 1990 (inclusive) and until the date of the literature search.

Exclusion criteria

- All non-English language literature, except Scandinavian.

- Literature without an available abstract.

- Literature reporting only psychological aspects.

\section{Deviations from protocol in search strategy}

Combining the three sets of entry terms resulted in 225 individual searches in each database. If any of these individual searches returned more than 700 results, the search was performed again with a fourth entry term (disaster prevention) using the Boolean operator AND (figure 1).

In Scopus, two entry terms, "questionnaires" and "learning", were excluded due to a large number of irrelevant results, and all searches were limited to the subject areas of life sciences, health sciences and physical sciences. Searches in Scopus were further limited to article title, abstract and keywords. In Web of Knowledge (ISI), all searches were limited to articles and reviews. The term "disaster prevention" was used to refine and decrease the number of search results in four of the individual searches performed in this database. ProQuest Research Library was excluded as it returned too many irrelevant results and the most relevant subjects were covered by the searches performed in PubMed/MEDLINE, Web of Knowledge and Scopus.

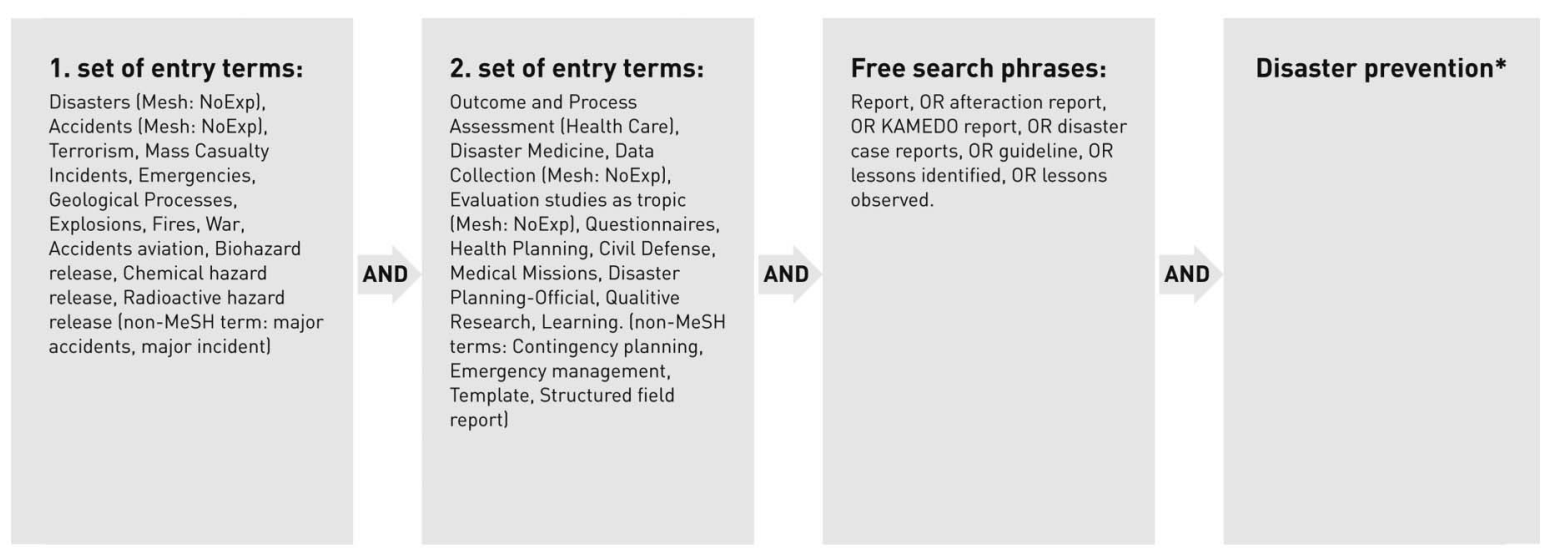

Figure 1 Search strategy. The two first sets of entry terms consisted of 15 terms each, and the third set of eight free search phrases. Combining these three sets resulted in 225 individual searches in each database. *If any of the individual searches returned more than 700 results, the search was performed again with a fourth entry term (disaster prevention) using the Boolean operator AND. 
The grey literature databases revealed a broad range of quality and searchability. The System for Information on Grey Literature in Europe (OpenSIGLE) was excluded due to the need to order the documents from the original source or a library. Only the document title was available on the web page, making it difficult to determine which documents to order.

Deviations in the search strategy were necessary in order to make the systematic literature review feasible, as a larger number of findings might have made completion of the study impossible.

\section{Search findings}

The search was performed according to the deviations described above. A total of 10136 results from each individual database search were sent to Endnote X5 (Thomson Reuters, New York, USA). After removing duplicates, the number of results was 8497 . The grey literature search returned 107 results (figure 2). A total of 18 articles were included for data extraction and quality appraisal.

\section{Analysis of identified literature}

One author scanned the titles and abstracts of the identified literature. Literature not complying with the inclusion criteria was excluded. The full text was obtained for uncertain articles, and inclusion was subject to consensus among three of the authors. Data analysis was performed according to the participants, interventions, comparisons, outcomes, study design (PICOS) methodology as described in PRISMA guidelines. ${ }^{20}{ }^{21}$ In this case, the participants were all the identified templates for reporting major incident medical management. Our intervention, comparisons and outcomes were carried out using the data extraction and quality appraisal variables described in methods and depicted in figures 3 and 4. From each template, 34 data items were extracted according to a predefined set of questions described in the study protocol ${ }^{19}$ (figure 3). These data were classified into four categories: demographics, incident characteristics, system characteristics and descriptors of patient characteristics. After data extraction, quality appraisal was conducted using a checklist $^{22}$ designed by the authors prior to data collection ${ }^{19}$ (figure 4). This checklist was based on authors' assumptions of the data relevant to report in a template. One author performed data extraction and quality appraisal; the results were checked by a second author. The contact authors of articles that provided an email address were asked whether the template had been used in real-life incidents. The reference lists of the included literature were scanned and relevant literature included. A quantitative synthesis (meta-analysis) was not performed. The preferred reporting items for systematic reviews and meta-analyses (PRISMA) guidelines were followed. ${ }^{20} 21$

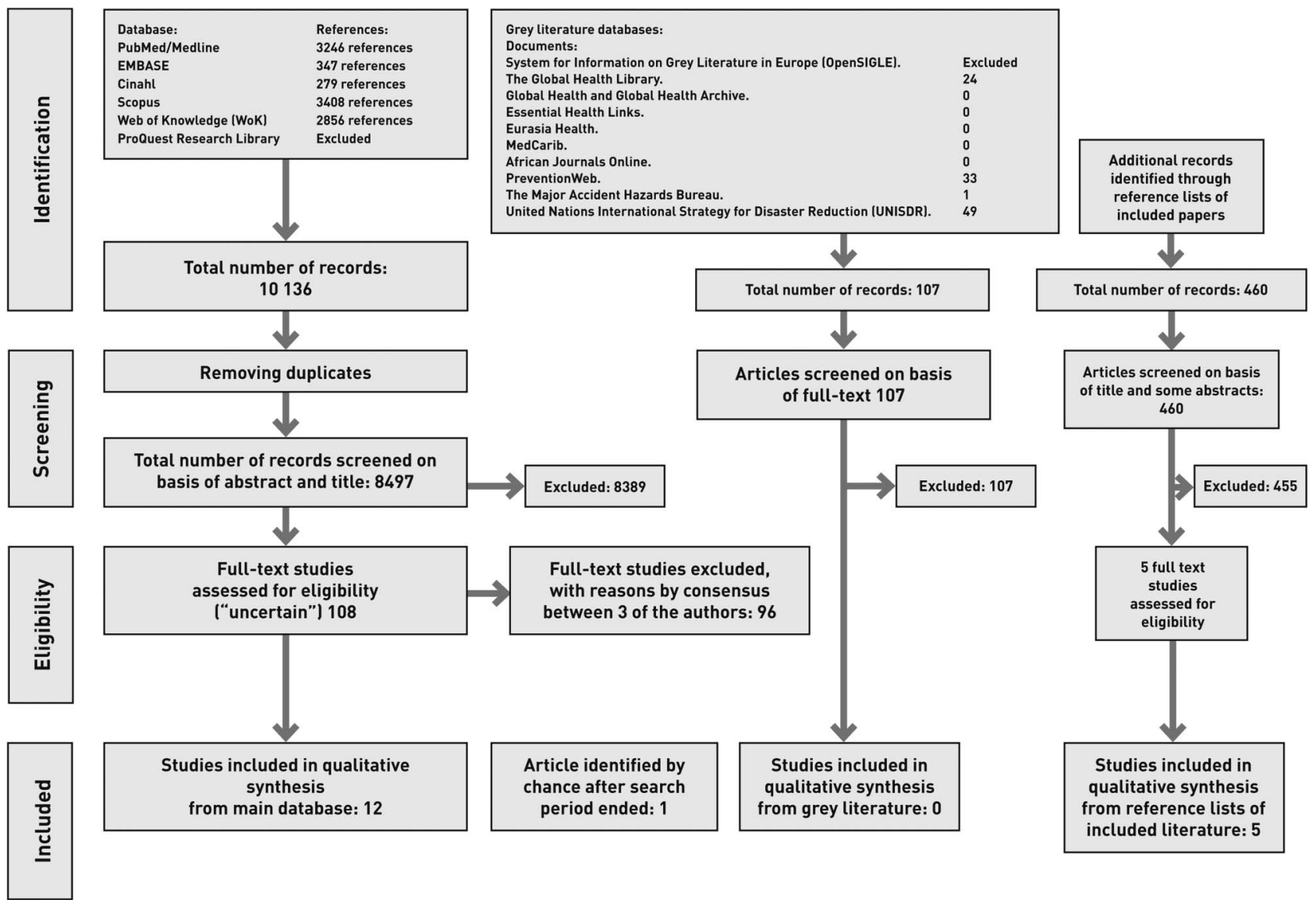

Figure 2 Flow diagram depicting the different stages of the systematic literature review. 


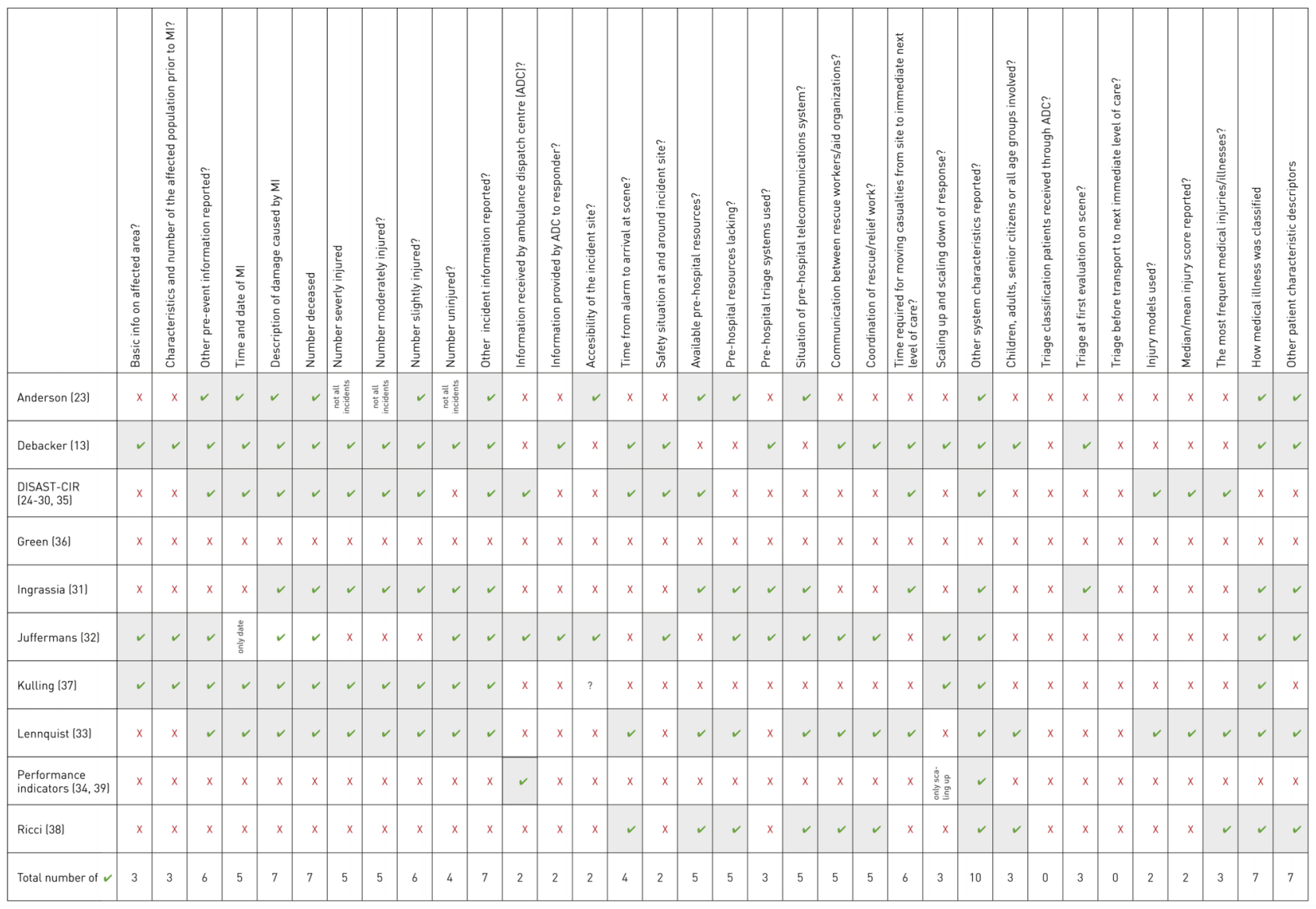

Figure 3 Data extraction from the included literature. $\checkmark$ Yes; $\times$ no; Ml, major incident.

Deviations from protocol regarding quality appraisal

The study protocol proposed to appraise whether the medical outcomes predicted by the templates were valid and to evaluate the outcome of using the templates. Both of these questions proved difficult to answer and were removed from the appraisal.

\section{RESULTS}

A total of 12 articles were included from the main database search, ${ }^{23-34}$ five articles were identified from the literature lists of included articles, ${ }^{35-39}$ and one relevant article was published after the literature search was completed $^{12}$ (figure 2). The total of 18 articles included 10 different templates or guidelines for reporting (figure 5).

\section{Data extraction}

The results of data extraction are shown in figure 3. In addition, under each of the four categories (pre-event information, incident information, system characteristics, patient characteristics), other information that was not extracted by the predefined questions was registered. Six of the 10 templates contained other pre-event information, such as climate, child mortality rate and descriptions of hazards. Seven of the 10 templates contained other incident information, such as a description of the incident. All templates included more system characteristics than what we extracted, including on-site medical care, distribution of casualties, independent action by medical disaster response personnel, continuation of day-to-day care, decision flow and information management. Seven templates contained other descriptors of patient characteristics, such as different triage systems used, description of psychological reactions and morbidity using hospital data.

\section{Quality appraisal}

The appraisal using a predefined checklist is shown in figure 4 . The first five questions regarding internal validity indicated that two of the templates contained none of the data we were looking for, four templates contained one of the data items we found relevant and the remaining four templates included three or more data items included in our list of desirable information. The 11 items regarding external validity were also heterogeneous in regard to which and how many of the items each template contained.

\section{Use of templates}

We succeeded in contacting the authors of seven templates. According to the authors, five of these templates $^{24-30} 31$ 33-35 3739 were used in other publications and one ${ }^{12}$ is currently being used to retrospectively evaluate disaster management. One has not been used 


\begin{tabular}{|c|c|c|c|c|c|c|c|c|c|c|}
\hline & 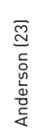 & 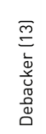 & 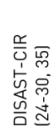 & 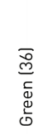 & 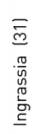 & 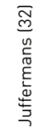 & 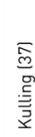 & 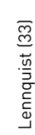 & 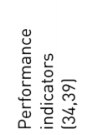 & $\begin{array}{l}\bar{\infty} \\
\overline{\tilde{g}} \\
\overline{\underline{y}} \\
\bar{x}\end{array}$ \\
\hline 1. Was the methodology for developing the template clearly explained? & $\mathrm{x}$ & v & $x$ & r & $\mathrm{x}$ & r & r & $\mathrm{x}$ & $\mathrm{x}$ & $\mathrm{x}$ \\
\hline 2. Are the data variables listed in the template clearly defined? & $x$ & $\checkmark$ & $\checkmark$ & r & $\mathrm{x}$ & $\mathrm{x}$ & r & v & r & $\mathrm{x}$ \\
\hline 3. Is the rationale for the data variables described? & $x$ & r & $x$ & 。 & r & r & r & $\mathrm{x}$ & $x$ & $\mathrm{x}$ \\
\hline 4. Is handling of missing data described? & $x$ & r & $x$ & r & $\mathrm{x}$ & $\mathrm{x}$ & v & $\mathrm{x}$ & $x$ & $\mathrm{x}$ \\
\hline 5. Has an ethics committee approved the template? & $x$ & $x$ & $x$ & r & $\mathrm{x}$ & v & $\mathrm{x}$ & $\mathrm{x}$ & $x$ & $\mathrm{x}$ \\
\hline 6a. Does the literature state who developed the template? & $x$ & r & r & r & $\mathrm{x}$ & $\mathrm{x}$ & 。 & $\mathrm{x}$ & v & $\mathrm{x}$ \\
\hline b. How the process was funded & $x$ & r & v & 。 & $\mathrm{x}$ & $x$ & r & $\mathrm{x}$ & $x$ & $\mathrm{x}$ \\
\hline 7a. Which continent/country/organization was the template developed in? & 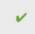 & $\checkmark$ & v & r & v & v & v & v & v & v \\
\hline b. Where (specific region) it is intended to be used? & $x$ & r & v & r & $\mathrm{x}$ & $\mathrm{x}$ & $\mathrm{x}$ & $\mathrm{x}$ & $x$ & $\mathrm{x}$ \\
\hline $\begin{array}{l}\text { 8. Are the data variables transferable to other countries or major } \\
\text { incident management systems? }\end{array}$ & $x$ & r & v & r & $\mathrm{x}$ & $x$ & r & r & v & $\mathrm{x}$ \\
\hline 9. Is it possible to report the incident timeline? & $x$ & r & v & 。 & $\mathrm{x}$ & r & - & . & $x$ & $\mathrm{x}$ \\
\hline 10. Is a valid discussion included about possible sources of bias? & $x$ & 。 & r & 。 & v & r & r & $\mathrm{x}$ & r & $\mathrm{x}$ \\
\hline 11. Do the authors discuss using the template as a tool for evaluation? & $\checkmark$ & $\checkmark$ & v & r & $\checkmark$ & v & r & v & v & r \\
\hline 12. Has the clinical credibility of the tool been evaluated? & $x$ & $\mathrm{x}$ & $\mathrm{x}$ & $\mathrm{x}$ & $\mathrm{x}$ & $\mathrm{x}$ & $\mathrm{x}$ & $\mathrm{x}$ & $x$ & $\mathrm{x}$ \\
\hline 13. Has the feasibility of the template been evaluated? & $x$ & $x$ & $\mathrm{x}$ & $\mathrm{x}$ & $\mathrm{x}$ & $\mathrm{x}$ & $\mathrm{x}$ & $\mathrm{x}$ & $x$ & $\mathrm{x}$ \\
\hline 14. Has the template been used in other publications? & ? & * & r & ? & $\checkmark$ & $\mathrm{x}$ & v & v & $v$ & ? \\
\hline
\end{tabular}

Figure 4 Quality appraisal of the included literature. $\checkmark$ Yes, $\times$ no, ? unclear, ${ }^{*}$ study is ongoing.

in other publications. ${ }^{32}$ DISAST-CIR ${ }^{24-30} 35$ is routinely used to report each mass casualty incident in the registry of the Israeli Defence Force Home Front and Ministry of Health. Guidelines for reporting health crises and critical health events ${ }^{37}$ have been used to report international disasters, but these publications were not available as official publications at the time of correspondence with the authors. The protocol for reports of major accidents and disasters ${ }^{33}$ was published previously in the International Journal of Disaster Medicine ${ }^{40}{ }^{41}$ and used for a report in this journal. ${ }^{42}$ It has also been used in the European Journal of Trauma and Emergency Surgery ${ }^{43} 44$ and mentioned in an editorial in the same journal. ${ }^{45}$ Two of the templates ${ }^{3134} 39$ are routinely used for reporting from exercises. Data on medical management during a mass casualty incident exercise ${ }^{31}$ are normally used to assess the healthcare system in a mass casualty incident simulation and exercise. An online registry for the healthcare system is designed using this instrument. Performance indicators for major incident medical management ${ }^{34} 39$ have also been used in additional publications. ${ }^{17}{ }^{46-50}$ For the three publications lacking author email, ${ }^{23} 3638$ we were unable to attain information on whether they have been used.

\section{DISCUSSION}

We identified 10 templates for reporting prehospital major incident medical management that were heterogeneous with regard to the data they reported. The quality appraisal revealed that, for most of the templates, the methodology for developing them was not clearly explained. In addition, the data variables were not clearly defined for all templates, and the rationale for choosing the data variables was only explained for half of the templates. Only three of the articles describe the handling of missing data and two depict whether an ethics committee approved the templates. All of these factors are important for internal validity, but the results were also heterogeneous for external validity. We chose to interpret that the templates were developed in the regions affiliated with the authors, though this was not specified. Only two templates stated in which region they were intended to be used. None of the articles discussed the clinical credibility of the template, and no feasibility studies have been performed. In all cases, the use of the template as a tool for evaluation was mentioned.

The data extraction and quality appraisal variables were based on the authors' assumptions on what is important in a template for reporting major incident medical management. Data variables for reporting should be uniformly defined in order to improve research and allow analysis of data; this is the ideological basis for several previous projects to standardise data for scientific use. $^{9-12}$ We also believe it is important that templates are preapproved by ethics committees to allow immediate reporting and rapid dissemination of data on 


\begin{tabular}{|c|c|c|c|c|}
\hline $\begin{array}{l}\text { Anderson, } 1995 \\
(23)\end{array}$ & $\begin{array}{l}\text { Debacker et al, } \\
2012 \text { (12) }\end{array}$ & $\begin{array}{l}\text { DISAST-CIR, 2007- } \\
2008(24-30,35)\end{array}$ & $\begin{array}{l}\text { Green et al, } \\
2003(36)\end{array}$ & $\begin{array}{l}\text { Ingrassia et al, } \\
2010(31)\end{array}$ \\
\hline $\begin{array}{l}\text { A comparative analysis of } \\
\text { the emergency medical } \\
\text { services and rescue } \\
\text { responses to eight } \\
\text { airliner crashes in the } \\
\text { United States, 1987- } \\
\text { 1991. }\end{array}$ & $\begin{array}{l}\text { Utstein-style template } \\
\text { for uniform data } \\
\text { reporting of acute } \\
\text { medical responses in } \\
\text { disaster. }\end{array}$ & $\begin{array}{l}\text { Seven articles using a } \\
\text { template (DISAST-CIR) } \\
\text { for reporting from mass } \\
\text { casualty incidents. } \\
\text { Documented in the } \\
\text { registry of the Israeli } \\
\text { Defence Force Home } \\
\text { Front and Ministry of } \\
\text { Health. }\end{array}$ & $\begin{array}{l}\text { Generic evaluation } \\
\text { methods for disaster } \\
\text { drills in developing } \\
\text { countries. }\end{array}$ & $\begin{array}{l}\text { Evaluation of medical } \\
\text { management during a } \\
\text { mass casualty incident } \\
\text { exercise. }\end{array}$ \\
\hline $\begin{array}{l}\text { Retrospective analysis of } \\
\text { real events using a } \\
\text { systematic method. }\end{array}$ & $\begin{array}{l}\text { Template for future } \\
\text { reporting of real } \\
\text { incidents. }\end{array}$ & $\begin{array}{l}\text { Systematic method for } \\
\text { reporting real incidents. }\end{array}$ & $\begin{array}{l}\text { Systematic method for } \\
\text { reporting from field } \\
\text { exercises. }\end{array}$ & $\begin{array}{l}\text { Systematic method for } \\
\text { reporting from field } \\
\text { exercises. }\end{array}$ \\
\hline $\begin{array}{l}\text { Juffermans et al, } \\
2010(32)\end{array}$ & $\begin{array}{l}\text { Kulling et al, } \\
2010 \text { (37) }\end{array}$ & $\begin{array}{l}\text { Lennquist, } 2008 \\
\text { (33) }\end{array}$ & $\begin{array}{l}\text { Performance } \\
\text { indicators, 2004, } \\
2010(34,39)\end{array}$ & $\begin{array}{l}\text { Ricci et al, } \\
1991 \text { (38) }\end{array}$ \\
\hline $\begin{array}{l}\text { Recurrent medical } \\
\text { response problems } \\
\text { during five recent } \\
\text { disasters in the } \\
\text { Netherlands. }\end{array}$ & $\begin{array}{l}\text { Guidelines for report on } \\
\text { health crisis and critical } \\
\text { health events. }\end{array}$ & $\begin{array}{l}\text { Protocol for Reports } \\
\text { from Major Accidents } \\
\text { and Disasters in the } \\
\text { International Journal of } \\
\text { Disaster Medicine. }\end{array}$ & $\begin{array}{l}\text { An evaluation tool for } \\
\text { reporting major incident } \\
\text { medical management } \\
\text { from disaster exercises. }\end{array}$ & $\begin{array}{l}\text { Assessment of Pre- } \\
\text { hospital and Hospital } \\
\text { Response in Disasters. }\end{array}$ \\
\hline $\begin{array}{l}\text { Retrospective analysis of } \\
\text { real events using a } \\
\text { systematic method. }\end{array}$ & $\begin{array}{l}\text { Guidelines for systematic } \\
\text { reporting from real } \\
\text { incidents. }\end{array}$ & $\begin{array}{l}\text { Guideline for systematic } \\
\text { reporting from real } \\
\text { incidents. }\end{array}$ & $\begin{array}{l}\text { Systematic method for } \\
\text { reporting from field } \\
\text { exercises. }\end{array}$ & $\begin{array}{l}\text { Guidelines for systematic } \\
\text { reporting from real } \\
\text { incidents. }\end{array}$ \\
\hline
\end{tabular}

Figure 5 An overview of the included literature.

the potential for improvement. For a template to be used, it needs to be both clinically credible and feasible. Ideally, if a template is to be used in a specific region, it ought to be developed together with experts from that region; if this is not possible, feasibility studies regarding regional differences could be performed. Reporting should be done by representatives with in-depth local knowledge and directly involved in responding to or managing the major incident. The ultimate goal of reporting is that an evaluation of the response be undertaken to identify areas for improvement, enabling those responsible in similar settings to improve their preparedness. For this kind of evaluation to occur, comparable, standardised reports that allow for research need to be published. Thus far, reporting on the scale needed for comparisons has not been achieved.

\section{Limitations}

Not all of the included literature was intended for prospectively reporting real-life incidents. However, in order to not overlook potentially relevant aspects of major incident reporting, the literature aimed to report from exercises $^{31} 343639$ and literature using a systematic method for reporting in general was included. ${ }^{23}{ }^{32}$ A clear weakness was that templates may exist in languages other than those included. We invite others to identify these templates. Only literature in which an abstract was available was included. With more that 8000 articles identified in the search, reviewing full articles at the initial stage was not feasible. Another limitation was that only one author performed the initial review of the literature for inclusion. One author performed data extraction and the appraisal and a second author checked the results, but this can still allow room for subjective interpretations of the content of the templates. The aim of the appraisal was to systematically extract information that the authors thought would be important for reporting major incident medical management. However, neither the data extraction nor the quality appraisal represents a validated set of data or gold standard.

\section{CONCLUSIONS}

Our findings show that more than one template exists for generating reports from the medical management of major incidents. Limitations are present in the existing templates regarding internal and external validity, and none of them have been tested for feasibility in real-life incidents. Uniform reporting can allow the analysis and comparison of medical management for different major incidents and identify areas that need improvement. Indirectly, this information can lead to better resource use and improved outcomes for patients and society. The 
identified templates may be used as a basis for designing a template that is specifically aimed at prehospital medical care and at generating reports in such a quantity that comparative analysis can be performed. The work to create such a template seems warranted and is now underway.

Contributors SF, MR and TW conceived the idea and designed the study. ER designed and conducted the search strategy for the literature search. SF screened the identified literature. TW, MR and SF considered the eligibility of uncertain literature. SF performed data extraction and quality appraisal of the included literature. TW and MR checked these results and were mentors in the process. SF, MR, ER and TW approved the final version of the manuscript.

Funding The Norwegian Air Ambulance employs SF and MR as research fellows. ER and TW received departmental funding only. No additional funding was obtained.

Competing interests None.

Provenance and peer review Not commissioned; externally peer reviewed.

Data sharing statement No additional data are available.

Open Access This is an Open Access article distributed in accordance with the Creative Commons Attribution Non Commercial (CC BY-NC 3.0) license which permits others to distribute, remix, adapt, build upon this work noncommercially, and license their derivative works on different terms, provided the original work is properly cited and the use is non-commercial. See: http:// creativecommons.org/licenses/by-nc/3.0/

\section{REFERENCES}

1. Guha-Sapir D, Vos F, Below R, et al. Annual Disaster Statistical Review 2011: The Numbers and Trends. Centre for Research on the Epidemiology of Disasters. Brussels 2012. http://cred.be/sites/ default/files/2012.07.05.ADSR_2011.pdf (accessed 31 Mar 2013).

2. Dara SI, Ashton RW, Farmer JC, et al. Worldwide disaster medica response: an historical perspective. Crit Care Med 2005;33:S2-6.

3. Bradt DA, Aitken P. Disaster medicine reporting: the need for new guidelines and the CONFIDE statement. Emerg Med Australas 2010;22:483-7.

4. Stratton SJ. Use of structured observational methods in disaster research: "Recurrent medical response problems in five recent disasters in the Netherlands". Prehosp Disaster Med 2010;25:137-8.

5. Stratton SJ. The Utstein-style template for uniform data reporting of acute medical response in disasters. Prehosp Disaster Med 2012;27:219.

6. Castren M, Hubloue I, Debacker M. Improving the science and evidence for the medical management of disasters: Utstein style. Eur J Emerg Med 2012;19:275-6.

7. Lockey DJ. The shootings in Oslo and Utoya island July 22, 2011: lessons for the International EMS community. Scand J Trauma Resusc Emerg Med 2012;20:4.

8. Lennquist S. Introduction to the third "Focus-on" issue specially devoted to papers within the field of the ESTES section for Disaster and Military Surgery. Eur J Trauma Emerg Surg 2011;37:1-2.

9. Langhelle A, Nolan J, Herlitz J, et al. Recommended guidelines for reviewing, reporting and conducting research on post-resuscitation care: the Utstein style. Resuscitation 2005:66:271-83.

10. Ringdal KG, Coats TJ, Lefering R, et al. The Utstein template for uniform reporting of data following major trauma: a joint revision by SCANTEM, TARN, DGU-TR and RITG. Scand J Trauma Resusc Emerg Med 2008;16:7.

11. Sundnes KO. Health disaster management: guidelines for evaluation and research in the Utstein style: executive summary. Task Force on Quality Control of Disaster Management. Prehosp Disaster Med 1999;14:43-52.

12. Debacker M, Hubloue I, Dhondt E, et al. Utstein-style template for uniform data reporting of acute medical response in disasters. PLoS Curr 2012;4:e4f6cf3e8df15a

13. Fevang E, Lockey D, Thompson J, et al. The top five research priorities in physician-provided pre-hospital critical care: a consensus report from a European research collaboration. Scand J Trauma Resusc Emerg Med 2011;19:57.

14. Mackway-Jones K, Carley S. An international expert Delphi study to determine research needs in major incident management. Prehosp Disaster Med 2012;27:351-8.
15. Ranse J, Hutton A. Minimum data set for mass-gathering health research and evaluation: a discussion paper. Prehosp Disaster Med 2012;27:1-8.

16. Legemaate GA, Burkle FM Jr, Bierens JJ. The evaluation of research methods during disaster exercises: applicability for improving disaster health management. Prehosp Disaster Med 2012;27:18-26.

17. Radestad $\mathrm{M}$, Nilsson $\mathrm{H}$, Castren $\mathrm{M}$, et al. Combining performance and outcome indicators can be used in a standardized way: a pilot study of two multidisciplinary, full-scale major aircraft exercises. Scand J Trauma Resusc Emerg Med 2012;20:58.

18. Clarke M. Evidence aid-from the Asian tsunami to the Wenchuan earthquake. J Evid Based Med 2008;1:9-11.

19. Fattah S, Rehn M, Reierth E, et al. Templates for reporting pre-hospital major incident medical management: systematic literature review. BMJ Open 2012;2:e001082.

20. Moher D, Liberati A, Tetzlaff J, et al. Preferred reporting items for systematic reviews and meta-analyses: the PRISMA statement. PLoS Med 2009;6:e1000097.

21. Liberati A, Altman DG, Tetzlaff J, et al. The PRISMA statement for reporting systematic reviews and meta-analyses of studies that evaluate health care interventions: explanation and elaboration. PLoS Med 2009;6:e1000100.

22. Whiting $P$, Harbord R, Kleijnen J. No role for quality scores in systematic reviews of diagnostic accuracy studies. BMC Med Res Methodol 2005;5:19.

23. Anderson PB. A comparative analysis of the emergency medical services and rescue responses to eight airliner crashes in the United States, 1987-1991. Prehosp Disaster Med 1995;10:142-53.

24. Bloch $\mathrm{YH}$, Schwartz D, Pinkert $M$, et al. Distribution of casualties in a mass-casualty incident with three local hospitals in the periphery of a densely populated area: lessons learned from the medical management of a terrorist attack. Prehosp Disaster Med 2007;22:186-92.

25. Leiba A, Schwartz D, Eran T, et al. DISAST-CIR: disastrous incidents systematic analysis through components, interactions and results: application to a large-scale train accident. J Emerg Med 2009;37:46-50.

26. Schwartz D, Bar-Dayan Y. Injury patterns in clashes between citizens and security forces during forced evacuation. Emerg Med J 2008;25:695-8.

27. Schwartz D, Ostfeld I, Bar-Dayan Y. A single, improvised "Kassam" rocket explosion can cause a mass casualty incident: a potential threat for future international terrorism? Emerg Med J 2009;26:293-8.

28. Raiter $Y$, Farfel A, Lehavi $\mathrm{O}$, et al. Mass casualty incident management, triage, injury distribution of casualties and rate of arrival of casualties at the hospitals: lessons from a suicide bomber attack in downtown Tel Aviv. Emerg Med J 2008;25:225-9.

29. Pinkert M, Lehavi O, Goren OB, et al. Primary triage, evacuation priorities and rapid primary distribution between adjacent hospitals-lessons learned from a suicide bomber attack in downtown Tel-Aviv. Prehosp Disaster Med 2008;23:337-41.

30. Pinkert M, Leiba A, Zaltsman E, et al. The significance of a small, level-3 'semi evacuation' hospital in a terrorist attack in a nearby town. Disasters 2007;31:227-35.

31. Ingrassia PL, Prato F, Geddo A, et al. Evaluation of medical management during a mass casualty incident exercise: an objective assessment tool to enhance direct observation. J Emerg Med 2010;39:629-36.

32. Juffermans J, Bierens JJ. Recurrent medical response problems during five recent disasters in the Netherlands. Prehosp Disaster Med 2010;25:127-36.

33. Lennquist S. Protocol for reports from major accidents and disasters in the International Journal of Disaster Medicine. Eur J Trauma Emerg Surg 2008;34:486-92.

34. Gryth D, Radestad M, Nilsson H, et al. Evaluation of medical command and control using performance indicators in a full-scale, major aircraft accident exercise. Prehosp Disaster Med 2010;25:118-23.

35. Schwartz D, Pinkert M, Leiba A, et al. Significance of a level-2, "selective, secondary evacuation" hospital during a peripheral town terrorist attack. Prehosp Disaster Med 2007;22:59-66.

36. Green GB, Modi S, Lunney K, et al. Generic evaluation methods for disaster drills in developing countries. Ann Emerg Med 2003;41:689-99.

37. Kulling $P$, Birnbaum M, Murray V, et al. Guidelines for reports on health crises and critical health events. Prehosp Disaster Med 2010;25:377-83.

38. Ricci E, Pretto E. Assessment of prehospital and hospital response in disaster. Crit Care Clin 1991;7:471-84.

39. Ruter AP, Wiström T. Performance indicators for major inciden medical management-a possible tool for quality control? Int $J$ Disaster Med 2004;2:52-5 
40. Lennquist S. Protocol for reports from major accidents and disasters in the International Journal of Disaster Medicine. Int J Disaster Med 2003;1:79-86.

41. Lennquist S. Protocol for reports from major accidents and disasters in the International Journal of Disaster Medicine. Int J Disaster Med 2004;2:57-64.

42. Backman K, Albertsson P, Petterson S, et al. Protocol from the coach crash in Ängelsberg, Sweden January 2003. Int J Disaster Med 2004;2:93-104.

43. Dami F, Fuchs V, Peclard E, et al. Coordination of emergency medical services for a major road traffic accident on a Swiss suburban highway. Eur J Trauma Emerg Surg 2009;35:265-70.

44. Marres GMH, Eijk JVD. Evaluation of admissions to the major incident hospital based on standardized protocol. Eur J Trauma Emerg Surg 2011;37:19-29.

45. Lennquist S. Introduction to the second "Focus on" disaster and military surgery. Eur J Trauma Emerg Surg 2009;35:199-200.
46. France JM, Nichols D, Dong S. Increasing emergency medicine residents' confidence in disaster management: use of an emergency department simulator and an expedited curriculum. Prehosp Disaster Med 2012;27:31-5.

47. Rüter $A$, Örtenwall $P$, Wikström T. Performance indicators for prehospital command and control in training of medical first responders. Int J Disaster Med 2004;2:89-92.

48. Rüter A, Wikstrom T. Improved staff procedyre skills lead to improved management skills: an observational study in an educational setting. Prehosp Disaster Med 2009;24:376-9.

49. Rüter A, Nilsson $\mathrm{H}$, Vilkström T. Performance indicators as quality control for testing and evaluating hospital management groups: a pilot study. Prehosp Disast Med 2006;21:423-6.

50. Rüter A, Vikström A. Indicateurs de performance: De la théorie a la pratique. Approche scientifique à propos de la medicine de catastrophe. Urgence Pratique 2009;93:41-4. 